\title{
La autodeterminación moderna: E1 derecho a la autonomía externa después de la Opinión Consultiva sobre Kosovo ${ }^{1}$
}

\author{
Modern Self-determination: The right to external autonomy after the Advisory Opinion on \\ Kosovo
}

\author{
Juan Manuel Indacochea Jauregui \\ jmindacochea@gmail.com
}

Colaborador de la Magistratura del Perú en el Tribunal de Justicia de la Comunidad Andina. Ex Consultor interno de la Magistratura de Bolivia del Tribunal de Justicia de la Comunidad Andina. Master en Derecho Internacional en la Universidad Paris-Ouest Nanterre La Défense, Master en Derecho de la Propiedad Intelectual en el CEIPI de la Universidad de Estrasburgo.

Resumen: En tiempos recientes, la práctica internacional viene brindando nuevos casos de secesiones pactadas, con el debido referéndum independentista de por medio, así como de rupturas violentas. Si bien las secesiones unilaterales no son bien vistas por la comunidad internacional, éstas no solo son posibles, sino que se han visto favorecidas con la Opinión Consultiva sobre Kosovo.

Palabras Clave: Autonomía, autodeterminación, democracia, independencia, Kosovo, Quebec.

\begin{abstract}
In recent times, the international practice has provided new cases of mutually agreed secession, as well as violent ruptures. Although the unilateral secessions are not well received by the international community, they are possible and the Advisory Opinion on Kosovo has favored them.
\end{abstract}

Keywords: Autonomy, Self-Determination, Democracy, Independence, Kosovo, Quebec.

1 Artículo enviado el 30.12.2017 y aceptado el 19.07.2018.

Número de página no utilizable para citar 


\section{Introducción}

No obstante el Parlamento escocés ya había votado - en marzo de 2017- en favor de dar a Nicola Sturgeon, la lideresa independentista, la autoridad para iniciar negociaciones sobre la realización de un segundo referéndum de independencia con el Parlamento de la Unión Europea ${ }^{3}$, Sturgeon finalmente decidió posponer el proyecto ${ }^{4}$. Sin embargo, se cree probable que lleve a cabo un referéndum antes del término de su mandato en $2021^{5}$.

Más del 92\% de los votantes en el referéndum del Kurdistán iraquí apoyaron la independencia; sin embargo, el entonces presidente se vio obligado a renunciar el 1 de noviembre de 2017, luego de que perdieran el control de extensos territorios en disputa y aislaran Erbil, la capital de la Región Autónoma Kurda ${ }^{6}$. Posteriormente, la Corte Suprema de Iraq incluso declaró el referéndum inconstitucional ${ }^{7}$.

En Cataluña, con posterioridad a que el gobierno central español activara el artículo 155 de la Constitución Española como consecuencia de que el Parlamento de Cataluña ${ }^{8}$ aprobara la

2 Keating, Joshua, "Learning to Live With a Changing World Map", en The New York Times, 22 de septiembre de 2017, disponible en: https://www.nytimes.com/2017/09/22/opinion/sunday/kurdistan-catalonia-independence.html [Consultada, 8 de agosto de 2018].

3 The Guardian, "Scottish parliament votes for second independence referendum", 28 de marzo de 2017, disponible en: https://www.theguardian.com/politics/2017/mar/28/scottish-parliament-votes-for-second-independence-referendumnicola-sturgeon [Consultada 8 de agosto de 2018].

4 The Guardian, "Nicola Sturgeon shelves second Scottish independence referendum", 27 de junio de 2017, disponible en: https://www.theguardian.com/politics/2017/jun/27/nicola-sturgeon-shelves-second-independence-referendum. [Consultada 8 de agosto de 2018].

5 The National, "Nicola Sturgeon to call vote on independence in 2018, says David Mundell”, 27 de febrero de 2018, disponible en: http://www.thenational.scot/news/16049709.Nicola_Sturgeon_to_call_vote_on_independence_in_2018_says_David_ Mundell/ [Consultada 8 de agosto de 2018].

6 El País, "El polémico referéndum independentista obliga al líder kurdo de Irak a dejar el poder", 30 de octubre de 2017, disponible en: https://elpais.com/internacional/2017/10/29/actualidad/1509296815_588983.html. [Consultada 8 de agosto de 2018].

7 BBC, disponible en: "Iraq Supreme Court rules Kurdish referendum unconstitutional", 20 de noviembre de 2017, disponible en: https://www.bbc.com/news/world-middle-east-42053283. [Consultada 8 de agosto de 2018].

8 El Parlamento de Cataluña o "Parlament de Catalunya" tendría sus orígenes en las Asambleas de Paz y Tregua y la Corte condal de la Edad Media; y la primera asamblea habría tenido lugar en Toluges, en el condado del Rosellón, en 1027. Parlament de Catalunya, "Historia", disponible en: https://www.parlament.cat/document/parlament/163820.pdf [Consultada 8 de agosto de 2018]. 
resolución para proclamar formalmente la independencia de la denominada República Catalana el 21 de diciembre de 2017, se llevaron a cabo elecciones autonómicas en Cataluña, convocadas justamente en virtud de la aplicación del artículo 155 de la Constitución Española ${ }^{10}$, en las cuales el independentismo revalidó su mayoría absoluta en el Parlamento de Cataluña ${ }^{11}$. Si bien ahora el gobierno español ha mostrado apertura a negociar un "pacto fiscal" ", ciertos informes sostienen que lo más conveniente para el pueblo catalán sería una "secesión pactada"13.

En marzo del presente año, se determinó la pregunta a ser planteada en el referéndum de independencia de Nueva Caledonia de 4 de noviembre: ¿Quiere que Nueva Caledonia acceda a la plena soberanía y sea independiente ${ }^{14}$ El referéndum de Nueva Caledonia supone la culminación de un proceso consensuado iniciado a partir de los Acuerdos de Matignon en junio de 1988, que previó un período de 10 años de desarrollo económico e institucional antes de realizar el referéndum. Sin embargo, el plazo inicialmente previsto fue pospuesto mediante la firma -por el entonces Primer Ministro francés Lionel Jospin- del Acuerdo de Numea. Este acuerdo disponía la realización del referéndum entre 2014 y 2018, y fue aprobado por el 70\% de la población neocaledonia ${ }^{15}$.

En virtud de los recientes acontecimientos comentados, es importante rexaminar el derecho a la libre determinación de los pueblos o derecho de autodeterminación, concentrándonos en la denominada "autodeterminación moderna", concebida por oposición al derecho a la libre determinación de los "pueblos sometidos a dominación colonial o a otras formas de dominación

9 El País, "El Senado aprueba aplicar el artículo 155 en Cataluña", 27 de octubre de 2017, disponible en: https://politica.elpais.com/politica/2017/10/27/actualidad/1509105725_777595.html. [Consultada 8 de agosto de 2018].

10 El País, "Rajoy destituye a Puigdemont y convoca elecciones en Cataluña el 21 de diciembre", 28 de octubre de 2017, disponible en: https://politica.elpais.com/politica/2017/10/27/actualidad/1509114362_109606.html?rel=mas. [Consultada 8 de agosto de 2018].

11 El Mundo, "Resultados de las elecciones catalanas en directo: Ciudadanos gana en votos y escaños; los independentistas suman mayoría absoluta", 22 de diciembre de 2017, disponible en: http://www.elmundo.es/cataluna/2017/12/21/5a3c30c2ca474108458b4604.html [Consultada 8 de agosto de 2018].

12 La Vanguardia, "El Gobierno está dispuesto a negociar un pacto fiscal para Catalunya, según "The Guardian", 21 de noviembre de 2017, disponible en: http://www.lavanguardia.com/politica/20171121/433053514302/gobierno-rajoypacto-fiscal-catalunya-the-guardian.html; el cual cita, además de la entrevista realizada al ministro de economía para el Financial Times, a The Guardian, "Spain 'ready to discuss' greater fiscal autonomy for Catalonia", 21 de noviembre de 2017, disponible en: https://www.theguardian.com/world/2017/nov/21/spain-ready-to-discuss-greater-fiscal-autonomy-forcatalonia. [Consultada 8 de agosto de 2018].

13 Frankfurter Allgemeine, "Sezession muss möglich sein”, 22 de noviembre de 2017, disponible en: http://www.faz.net/aktuell/wirtschaft/warum-sezessionen-moeglich-sein-muessen-kommentar-15303654.html. Véase también, La V anguardia, "Un informe avala la secesión pactada como vía más rentable para Catalunya", 16 de julio de 2015, disponible en: http://www.lavanguardia.com/politica/20150715/54433411341/informe-secesion-pactada-rentablecatalunya.html. Véase además, Diario, "La independencia 'pactada' es el mejor escenario de futuro para Cataluña, según un informe", 15 de julio de 2015, disponible en: http:/ /www.eldiario.es/politica/independencia-pactada-escenario-Catalunainforme_0_409459556.html. [Consultada 8 de agosto de 2018].

14 Le Monde, "Nouvelle-Calédonie: compromis sur la question posée lors du référendum d'indépendance", 28 de marzo de 2018, disponible en: https://www.lemonde.fr/politique/article/2018/03/28/nouvelle-caledonie-un-compromis-a-etetrouve-sur-la-question-posee-lors-du-referendum-d-independance_5277257_823448.html [Consultada 8 de agosto de 2018].

15 Sud Ouest, "Nouvelle-Calédonie: le référendum sur l'indépendance en cinq questions", 3 de mayo de 2018, disponible en: https://www.sudouest.fr/2018/05/03/nouvelle-caledonie-le-referendum-sur-l-independance-en-cinq-questions-5025975710.php[Consultada 8 de agosto de 2018].

Número de página no utilizable para citar 
La autodeterminación moderna

Juan Manuel Indacochea Jauregui

u ocupación extranjeras" (Resolución 50/6 de la Asamblea General de las Naciones Unidas AGNU) ${ }^{16}$.

El presente artículo expondrá los supuestos teóricos y prácticos de ejercicio del derecho a la libre determinación desarrolladas por la jurisprudencia y la doctrina (I), para posteriormente intentar identificar nuevos supuestos de ejercicio del derecho a la libre determinación sobre la base de la práctica internacional (II), realizando a los largo del presente estudio el correspondiente paralelo con los casos referidos precedentemente.

\section{Supuesto universalmente admitidos de autodeterminación}

La Corte Internacional de Justicia (en lo sucesivo, la CIJ) desarrolló el tema de la autodeterminación en la Opinión Consultiva sobre el "Sahara Occidental" de 1975, en el contexto de la descolonización, confirmando el derecho a la misma ${ }^{17}$. Un caso similar lo comportó el de "Namibia" de 1971, en el contexto de la ocupación pero abordado de manera marginal, atribuyéndole escasa importancia. De manera similar, en el caso "Consecuencias Jurídicas de la Construcción de un Muro en el Territorio Palestino Ocupado" de 2004, no obstante la CIJ determinó que el derecho a la autodeterminación del pueblo palestino había sido violado $^{18}$, éste desempeñó igualmente un papel secundario.

Es preciso destacar que en el asunto relativo a Timor Oriental, el derecho a la autodeterminación de los pueblos fue considerado como una norma oponible erga omnes ${ }^{19}$, aunque igualmente en un contexto de colonización u ocupación dado que el territorio fue ocupado por Indonesia luego de su independencia -descolonización- de Portugal.

Por otra parte, la "Declaración sobre la concesión de la independencia a los países y pueblos coloniales”, aprobada por la Resolución 1514 (XV) de la AGNU el 14 de diciembre de 1960 manifestaba en sus considerandos: "Creyendo que el proceso de liberación es irresistible e irreversible y que, a fin de evitar crisis graves, es preciso poner fin al colonialismo y a todas las prácticas de segregación y discriminación que lo acompañan [...]". Posteriormente, la AGNU adoptaría la "Declaración de las Naciones Unidas sobre la eliminación de todas las formas de discriminación racial” mediante la Resolución 1904 (XVIII) de 20 de noviembre de 1963, la cual

16 Resolución 50/6 de la Asamblea General de 9 de noviembre de 1995.

17 CIJ, Opinión Consultiva sobre el caso relativo al "Sahara Occidental”, de 16 de octubre de 1975, párr. 70.

18 CIJ, Opinión Consultiva sobre las "Consecuencias jurídicas de la construcción de un muro en el territorio palestino ocupado”, de 9 de julio de 2004, párr. 184.

19 CIJ, fallo sobre el caso relativo a "Timor Oriental" (Portugal c. Australia), sentencia de 30 de junio de 1995, en ICJ Reports 1995, párr. 90.

Número de página no utilizable para citar 
reafirmaba en su cuarto considerando lo siguiente: "Considerando que las Naciones Unidas han condenado el colonialismo y todas las prácticas de segregación y discriminación que lo acompañan, y que la Declaración sobre la concesión de la independencia a los países y pueblos coloniales proclama entre otras cosas la necesidad de poner fin al colonialismo rápida e incondicionalmente $[\ldots]$ ".

Adicionalmente, la Resolución 2131 (XX) de la AGNU de 21 de diciembre de 1965, aprobó la "Declaración sobre la inadmisibilidad de la intervención en los asuntos internos de los estados y protección de su independencia y soberanía", la cual invocaba a los Estados a "contribuir a la eliminación completa de la discriminación racial y del colonialismo en todas sus formas y manifestaciones" ${ }^{20}$; principios que serían reiterados y cuyo contenido sería ampliado mediante diversas resoluciones de la AGNU (e.g., 1970, 1973, etc.), entre las cuales cabe destacar la Resolución 36/103 de la AGNU de 9 de diciembre de 1981, que contiene la "Declaración sobre la Inadmisibilidad de la Intervención y la Injerencia en los Asuntos Internos de los Estados"21, cuya tercera parte (2.III.c) reconoce:

"El derecho y el deber de los Estados de apoyar plenamente el derecho a la libre determinación, la libertad y la independencia de los pueblos sometidos a dominación colonial, ocupación extranjera o regímenes racistas, así como su derecho de librar una lucha política y armada con este fin, de conformidad con los propósitos y principios de la Carta."22

En consecuencia, es posible observar que la CIJ comenzó a construir el principio de libre determinación de los pueblos hasta convertirlo en una costumbre internacional de carácter universal y, posteriormente, en una norma imperativa de derecho internacional general (ius cogens), para solo tres casos: (i) pueblos sometidos a dominación colonial; (ii) pueblos sometidos a ocupación extranjera; y, (iii) regímenes racistas. En otras palabras, la CIJ inicialmente forjó el derecho a la libre determinación únicamente sobre la base de tres supuestos:

20 Cabe destacar que el mismo 21 de diciembre de 1965, mediante Resolución 2106 A (XX) de la AGNU, se adoptó la "Convención Internacional sobre la Eliminación de todas las Formas de Discriminación Racial".

21 Cabe destacar que el sexto considerando de la Resolución 36/103 hace referencia directa a la problemática de la descolonización, aunque más de dos décadas después de iniciada la participación de las Naciones Unidas en dicho proceso: "Consciente de la necesidad imperiosa de que todas la fuerzas extranjeras que participan en actos de ocupación, intervención o injerencia militar se retiren completamente a sus propios territorios a fin de que los pueblos sometidos a dominación colonial, ocupación extranjera o regímenes racistas puedan ejercer libre y plenamente su derecho a la libre determinación, de manera que los pueblos de todos los Estados puedan administrar sus propios asuntos y determinar su propio sistema político, económico y social sin injerencia o control del exterior".

22 El apartado 4, por su parte, advierte lo siguiente: "Nada de cuanto contiene la presente Declaración menoscabará en modo alguno el derecho a la libre determinación, la libertad e independencia de los pueblos sometidos a dominación colonial, ocupación extranjera o regímenes racistas ni su derecho a procurar y recibir apoyo de conformidad con los propósitos y principios de la Carta". 
(i) Pueblos coloniales que buscan independizarse de una metrópoli (e.g., Sahara Occidental);

(ii) Pueblos que buscan expulsar tropas invasoras extranjeras (e.g., Consecuencias Jurídicas de la Construcción de un Muro en el Territorio Palestino Ocupado);

(iii) Pueblos que buscan derrocar un régimen racista al interior de sus fronteras (e.g., SWAPO contra el régimen racista sudafricano).

La consagración como norma imperativa de derecho internacional general llegó el 29 de noviembre de 1991, cuando la Comisión de Arbitraje de la Conferencia para la Paz en Yugoslavia, en su Opinión ("Avis") n $\mathrm{n}^{\circ}$, calificó el derecho a la autodeterminación de los pueblos de principio estructural del derecho internacional, considerándolo un fiel reflejo de la categoría de normas imperativas o de ius cogens ${ }^{23}$.

Sin embargo, a partir de la Opinión Consultiva emitida por la Corte Internacional de Justicia (CIJ) sobre Kosovo ${ }^{24}$, en la cual la CIJ citó ${ }^{25}$ el pronunciamiento de la Corte Suprema de Canadá sobre la secesión de Quebec ${ }^{26}$, ha surgido una fuerte polémica acerca de cómo interpretar ambos pronunciamientos, así como respecto de sus alcances. No obstante ambos pronunciamientos difieren en los medios ${ }^{27}$, la otra gran incertidumbre supone la posibilidad de haber legitimado nuevos supuestos y -pueblos- destinatarios del derecho a la libre determinación.

Frecuentemente, se le critica a la CIJ el haber desaprovechado, al emitir la Opinión Consultiva sobre la conformidad con el derecho internacional de la declaración unilateral de independencia (DUI) relativa a Kosovo de 22 de julio de 2010, una oportunidad única de tratar los temas de la "secesión como remedio" ("remedial secession") ${ }^{28}$ y la "autodeterminación moderna" 29 . Sin embargo, en relación con la posibilidad de tratar el tema de la "secesión como remedio", es

23 Artículo 53 del Convenio de Viena sobre los Tratados de 1969. "Avis" disponible en Revue générale de droit international public (Editions A. Pedone: Paris, 1992), p. 265.

24 CIJ, "Opinión Consultiva sobre la conformidad con el derecho internacional de la declaración unilateral de independencia relativa a Kosovo”, 22 de julio de 2010, disponible en: http://www.icj-cij.org/files/case-related/141/141-20100722-ADV01-00-EN.pdf [Consultada 8 de agosto de 2018].

25 CIJ, "Opinión Consultiva... Kosovo", párrs. 55-56.

26 Supreme Court of Canada, Reference re Secession of Quebec, [1998] 2 S.C.R. 217, párr. 155, "Reference by the Governor in Council concerning Certain Questions relating to the Secession of Quebec from Canada", disponible en: https://www.canlii.org/en/ca/scc/doc/1998/1998canlii793/1998canlii793.html [Consultada 8 de agosto de 2018].

27 Mientras la Opinión Consultiva sobre Kosovo legitimaría una independencia no negociada o unilateral, el Avis sobre Quebec solo plantea la posibilidad de una "secesión pactada".

28 Véase, un estudio bastante completo sobre la teoría de Buchanan en relación a la secesión como remedio, Mueller, Charlotte, "Secession and self-determination - Remedial Right Only Theory scrutinised", en Polis Journal (University of Leeds), Vol. 7, 2012, disponible en: http://www.polis.leeds.ac.uk/assets/files/students/student-journal/ug-summer12/ charlotte-mueller.pdf [Consultada 8 de agosto de 2018].

29 Véase, por ejemplo, Burri, Thomas, "The Kosovo Opinion and Secession: The Sounds of Silence and Missing Links", en German Law Journal, Vol. 11, n 07/08, 2010, pp. 888-889, disponible en: https://static1.squarespace.com/static/56330ad3e4b0733dcc0c8495/t/56b7e02e4c2f8550cdaf7dab/1454891054391/GLJ _Vol_11_No_08_Burri.pdf [Consultada 8 de agosto de 2018]. 
legítimo inferir que la CIJ no lo habría abordado simplemente debido a que probablemente consideró que la situación de Kosovo, en ese preciso momento - con posterioridad a 2008- no lo meritaba o porque simplemente, como se explicará más adelante, podía ser peligroso dar un paso tan grande.

Concretamente, la CIJ simplemente confirmó que no existe una norma de derecho internacional que prohíba a una entidad declarar su independencia, sin embargo, permaneció en silencio respecto de las consecuencias de tal declaración y si "efectivizar la independencia" ("effecting independence") podría contravenir o no el derecho internacional. Toda vez que el pronunciamiento es estrictamente limitado a la cuestión de la legalidad o conformidad con el derecho internacional general de la DUI, sería muy difícil interpretarlo en el sentido de que existiría un derecho a la secesión de Kosovo ${ }^{30}$.

En efecto, la situación de Kosovo en 2008 no habría justificado una "secesión como remedio", a diferencia, por ejemplo, de la situación de prolongada guerra civil, crisis humanitaria extrema y graves violaciones de derechos humanos en Sudán del Sur con anterioridad al Acuerdo General de Paz de 2005, donde una "secesión como remedio" hubiera estado plenamente justificada en el hipotético caso de no haber contado con el consentimiento formal del gobierno central de Sudán para la celebración de un referéndum vinculante de independencia, en el cual la opción secesionista fuera apoyada por una abrumadora mayoría de la población. A diferencia del caso de Kosovo, Sudán del Sur es un Estado creado con la aprobación del Estado predecesor. El mecanismo para la secesión estaba enraizado en el Acuerdo General de Paz de 2005 y en el acuerdo constitucional que resultó de éste. Por lo tanto, Sudán del Sur es un raro ejemplo de ejercicio de un derecho a la independencia en virtud de disposiciones constitucionales nacionales $^{31}$, y, por consiguiente, uno de los pocos casos de "secesión pactada".

Adicionalmente, la Resolución 1244 del Consejo de Seguridad de las Naciones Unidas (en adelante, el CS) ya había proporcionado a Kosovo un régimen de autonomía satisfactorio. Igualmente, la situación de graves violaciones de derechos humanos padecida principalmente entre 1996 y 1999 -año en que interviene la Organización del Tratado del Atlántico Norte (OTAN) - ya había sido superada. Asimismo, el régimen político serbio había sufrido profundos cambios desde 1999, de modo que permitía esperar otra actitud y conducta por parte de sus autoridades con respecto al pueblo kosovar ${ }^{32}$.

30 McKenna, Miriam, "Remedial Secession: Emerging Right or Hollow Rhetoric?”, Universidad de Lund, Tesis de Maestría, diciembre de 2010, p. 78, disponible en: http://portal.research.lu.se/portal/en/publications/remedial-secession-emergingright-or-hollow-rhetoric(dcb487ca-6e0b-410a-a24f-cc8fc868fdf3).html [Consultada 8 de agosto de 2018].

31 Vidmar, Jure, "South Sudan and the International Legal Framework", en Texas International Law Journal, Vol. 47, Issue 32012, p. 553, disponible en: http://www.tilj.org/content/journal/47/num3/Vidmar541.pdf [Consultada 8 de agosto de 2018].

32 Véase, en ese sentido, Jiménez Piernas, Carlos, "Los principios de soberanía e integridad territorial y de autodeterminación de los pueblos en la Opinión Consultiva sobre Kosovo: una oportunidad perdida", en Revista Española de Derecho Internacional, Vol. LXIII/1, Madrid, enero-junio 2011, p. 46, disponible en: http://bibliotecaculturajuridica.com/biblioteca/arxius/PDF/REDI_Vol._LXIII_1_2011/02_Jimenez_digital.pdf. 
Si bien la CIJ - en la mencionada Opinión Consultiva - determinó que la DUI de Kosovo era conforme con el derecho internacional general, no se pronunció acerca de la secesión de Kosovo del territorio serbio. En efecto, la CIJ precisó los efectos jurídicos de la DUI promulgada en Kosovo, evitando así manifestarse respecto de una eventual "secesión como remedio" "“remedial secession"), pero dejando así la puerta abierta a futuros casos de secesión de otros pueblos no sometidos a "dominación colonial o a otras formas de dominación u ocupación extranjeras" (Resolución 50/6 de la AGNU).

Adicionalmente, es preciso tener en consideración que, Kosovo no cumplía con el requisito de estatalidad referido a la necesidad de controlar exclusiva y excluyentemente el territorio ${ }^{33}$, exigido por el derecho internacional, dado que ni siquiera la MINUK ("Mission d'administration intérimaire des Nations Unies au Kosovo") controlaba el norte de Kosovo en 2008, por lo que ciertos Estados alegaron que el reconocimiento de Kosovo habría sido "prematuro" ${ }^{34}$, aunque la Opinión Consultiva analizada pareciera negar implícitamente la ilegalidad de tal reconocimiento ${ }^{35}$.

Es preciso entender la Opinión Consultiva sobre Kosovo de manera literal, en cuanto a lo expresamente manifestado y lo omitido. De lo contrario, se podría llegar a convalidar las independencias de facto, con escaso reconocimiento internacional, de Abjasia y de Osetia del Sur, tomando en consideración los actos de limpieza étnica ocurridos previamente a la intervención rusa en territorio georgiano ${ }^{36}$. Es lo que se denomina una reacción en cadena al aplicar conceptos teóricos que -según ciertos autores favorables a la causa rusa- podría incluso ser considerada como una práctica internacional emergente ${ }^{37}$; en un claro esfuerzo por justificar la anexión de Crimea como un caso de "secesión como remedio".

Como advirtió el Juez Koroma en su opinión disidente de la Opinión Consultiva sobre Kosovo, la afirmación de que el derecho internacional ni permite ni prohíbe las DUI sólo tiene sentido si

Véase además, en el mismo sentido, las exposiciones escritas de Argentina (párrs. 83-86), Rumanía (párrs. 132-159), Chipre (párrs. 140-148) e Irán (párrs. 4.1-4.2); así como las exposiciones orales de Rusia (Gevorgian), CR 2009/30 (párrs. 19-22 y 55-59), y China (Xue), CR 2009/29 (párrs. 24-26) [Consultada 10 de Agosto de 2018].

33 A este respecto, cabe precisar que en principio no se consideraba el requisito señalado, sino únicamente aquellos de población y territorio. Deutsche Continental Gas-Gesellschaft v. État polonais, Laudo de 1 de agosto de 1929, IX Recueil des Décisions des Tribunaux Arbitrales Mixtes (1930), p. 344. Tales criterios han sido reiterados en otros laudos arbitrales, como por ejemplo, Arbitration Commission of the International Conference on Yugoslavia (Badinter Arbitration Commission) en su Primera Opinión adoptada el 29 de noviembre de 1991, en cuyo punto (b) estableció : "the state is commonly defined as a community which consists of a territory and a population subject to an organized political authority;" véase 31 ILM 1494 (1992).

34 Véase, acerca de reconocimientos "prematuros", Corten, Olivier, "Déclarations unilatérales d'indépendance et reconnaissances prématurées du Kosovo à l'Ossétie du sud et à l'Abkhazie”, en Revue Générale de Droit International Public, 2008, pp. 721-760.

35 Vidmar, Jure, “The Kosovo Advisory Opinion Scrutinized”, en LJIL n² 24, 2011, pp. 368 y ss.

36 Pechalova, Tanita, "Remedial secession as right of self-determination: The cases of Kosovo and Abkhazia", Tilburg University Law School, Tesis de Maestría, junio de 2017, p. 72, disponible en: http://arno.uvt.nl/show.cgi?fid=143955 [Consultada 8 de agosto de 2018].

37 Véase, por ejemplo, Kapustin, Anatoly, "Crimea's Self-Determination in the Light of Contemporary International Law", Max-Planck-Institut für ausländisches öffentliches Recht und Völkerrecht, p. 107, disponible en: www.zaoerv.de/75_2015/75_2015_1_a_101_118.pdf [Consultada 8 de agosto de 2018]. 
se realiza en abstracto, no en un caso concreto, en el que en función de las circunstancias una DUI puede ser contraria al Derecho internacional ${ }^{38}$.

A este respecto, en la Opinión Consultiva sobre Kosovo se explicó, a propósito de las alegaciones -formuladas por varios Estados participantes- referidas a que el CS había condenado determinadas DUI (Rhodesia del Sur, Chipre septentrional y de la República Srpska), que en todos esos casos éste se había pronunciado respecto de cada situación concreta que existía al momento de promulgar las DUI y, por ende, la ilegalidad de éstas no derivaba de su carácter unilateral, sino del hecho que iban o habrían ido acompañadas de un uso ilícito de la fuerza o de otras graves infracciones a normas de derecho internacional general, en particular a aquellas de carácter imperativo (ius cogens) ${ }^{39}$.

Sin embargo, tal parece ser el razonamiento de la CIJ -según el propio Juez Simma ${ }^{40}$, es decir, que en relación con un acto específico no es necesario demostrar una norma permisiva en tanto no exista una prohibición (teoría de la libertad residual) ${ }^{41}$. Ello sería justamente consecuencia de haberse limitado a pronunciarse respecto de la DUI como un acto aislado y no sobre la posibilidad de secesión, que era al fin y al cabo lo que realmente estaba en juego ${ }^{42}$.

No obstante, como Robert Muharremi sugiere: "en tanto no existe una norma de derecho internacional que prohíba una DUI, se podría argumentar que tampoco existe una norma de

38 Opinión disidente del Juez Koroma, párr. 20. Por su parte, el Juez Bennouna, en su opinión disidente, criticó que la CIJ se centrara en la DUI en abstracto, sin indagar acerca del contexto particular en el cual se adoptó el acto consultado, es decir, sin preocuparse de los antecedentes de tal adopción ni quiénes fueron sus autores.

39 CIJ, "Opinión Consultiva... Kosovo", párr. 81.

40 Según el Juez Simma, al examinar únicamente la existencia de una norma de derecho internacional que prohíba las DUI, la CIJ volvió a acoger el principio del caso "Lotus" (elaborado por la Corte Permanente más de 80 años antes) y regresó al positivismo del siglo XIX, adoptando de esta manera una visión anacrónica y sumamente consensualista del derecho internacional (creencia en la completitud del derecho internacional sustantivo), por lo que tal razonamiento sería obsoleto. Sin embargo, como ilustra Muharremi, tal principio ya había sido confirmado por la CIJ en anteriores oportunidades: "The Lotus-Presumption was confirmed in subsequent ICJ case-law, e.g. the Nicaragua Judgment, and the Advisory Opinion on the Legality of the Threat or Use of Nuclear Weapons, and was applied in relations between states. In the present opinion, the ICJ applies the Lotus-Presumption to an entity declaring its independence, which may or may not yet be a state. This raises the question of whether the ICJ has extended the Lotus-Presumption to be applicable as a general principle of international law, which is not confined to relations between states, but which also applies to entities which could be considered states in statu nascendi, peoples in the exercise of their right to external self- determination, or peoples seceding and establishing a new state based on the principle of effectiveness outside the ambit of the right of selfdetermination". Muharremi, Robert, "A Note on the ICJ Advisory Opinion on Kosovo", en German Law Journal, Vol. 11, $\mathrm{n}^{\circ} 07 / 08,2010$, p. 876, disponible en:

https://static1.squarespace.com/static/56330ad3e4b0733dcc0c8495/t/56b7e0154c2f8550cdaf7d46/1454891030280/GLJ _Vol_11_No_08_Muharremi.pdf [Consultada 8 de agosto de 2018].

Casos precedentes de la CIJ referidos por Muharremi: Actividades militares y paramilitares contra el Gobierno de Nicaragua (Nicaragua c. Estados Unidos), 1986, párr. 269; Opinión consultiva de la Corte Internacional de Justicia sobre la licitud del empleo de armas nucleares, 1996, párr. 52.

41 Cabe precisar que, si bien el Juez Simma concuerda con la CIJ en la mayoría de sus argumentos, cuestiona el carácter limitado de su análisis, considerando que tanto las normas prohibitivas como las normas permisivas de derecho internacional general deberían haber sido objeto de un tratamiento más completo.

42 En ese sentido, Peters, Anne, "Does Kosovo Lie in the Lotus-Land of Freedom?", en Leiden Journal of International Law $\mathrm{n}^{\circ}$ 24, 2011, pp. 95-108, disponible en: http://edoc.unibas.ch/20647/1/20110215144916_4d5a845cde800.pdf [Consultada 8 de agosto de 2018]. 
derecho internacional que prohíba las secesiones"43. Para otros autores, la CIJ no ha negado la existencia del derecho de secesión, por lo que se trataría propiamente de un derecho -y una práctica- en calidad emergente, que ha sido -y continúa siendo- objeto de una fuerte oposición internacional. Sin embargo, cabe apuntar que el hecho de haber sido invocado por diversos Estados participantes en la Opinión Consultiva sobre Kosovo de 22 de julio de 2010 ha conllevado a su fortalecimiento ${ }^{44}$.

En consecuencia, según este pronunciamiento de la CIJ, una DUI no sería a priori contraria al derecho internacional; por el contrario, sería conforme a éste ${ }^{45}$, siempre que no concurran otras circunstancias que podrían acarrear su ilicitud (e.g., graves violaciones a los derechos humanos o al derecho internacional humanitario). De igual manera, el derecho internacional se mantendría -en principio- neutral ante el acto de secesión ${ }^{46}$.

43 "Therefore, since there is no rule of international law, which prohibits a declaration of independence, one could argue that there is also no norm of international law, which prohibits secessions". Muharremi, "A Note on the ICJ Advisory Opinion...", p. 880.

44 En ese sentido, Cirkovic, Elena, “An Analysis of the ICJ Advisory Opinion on Kosovo's Unilateral Declaration of Independence”, en German Law Journal, Vol. 11, n 07/08, 2010, disponible en: https://static1.squarespace.com/static/56330ad3e4b0733dcc0c8495/t/56b7e0674c2f8550cdaf7eb5/1454891112046/GLJ _Vol_11_No_08_Cirkovic.pdf [Consultada 10 de Agosto de 2018].

45 La doctrina mayoritaria sostiene la misma opinión, derivada de la Opinión Consultiva de la CIJ sobre Kosovo, de 22 de julio de 2010. Véase, por ejemplo, la reciente entrevista realizada al internacionalista Marcelo Kohen: "La Cour internationale de justice a dit qu'une déclaration unilatérale ne viole pas le droit international, car c'est une simple déclaration d’intention". ("La Corte Internacional de Justicia ha dicho que una declaración unilateral no viola el derecho internacional, porque es una simple declaración de intención”). Kohen, Marcelo, "Pour le droit international, il ne s'est rien passé à Barcelone", entrevista realizada por Simon Petite, en Le Temps, 27 de octubre de 2017, disponible en: https://www.letemps.ch/monde/2017/10/27/marcelo-kohen-droit-international-ne-sest-rien-passe-barcelone. Véase también, la conclusión del artículo de Elena Cirkovic: "Indeed, international law does not contain clear rules on how to respond to declarations of independence. The Court was not requested to provide an opinion on the principle of recognition by other states. Declarations of independence depend on the act of recognition by other states [...]" ("De hecho, el derecho internacional no contiene normas claras sobre cómo responder a las declaraciones de independencia. No se pidió a la Corte que proporcionase una opinión respecto del principio de reconocimiento por parte de otros Estados. Las declaraciones de independencia dependen del acto de reconocimiento de otros Estados [...]"). Cirkovic, "An Analysis of the ICJ Advisory Opinion...", p. 912; véase asimismo, la conclusión a la cual llega Jure Vidmar: "Catalonia does not have a right to independence, and at the same time it is not doing anything illegal internationally when claiming or declaring independence. For better or worse, this is everything that the international law of statehood has to say on the matter. The rest is a political game". ("Cataluña no tiene un derecho a la independencia, y al mismo tiempo no está no está haciendo nada internacionalmente ilegal al reivindicar o declarar la independencia. Para bien o para mal, esto es todo lo que el derecho internacional del statehood tiene que decir al respecto. Lo demás es un juego político").Vidmar, Jure, "Catalonia: The Way Forward is Comparative Constitutional Rather than International Legal Argument", en EJIL Talk, 24 de octubre de 2017, disponible en: https://www.ejiltalk.org/catalonia-the-way-forward-is-comparative-constitutionalrather-than-international-legal-argument/; y en Law Blogs Maastricht, Maastricht University, 25 de octubre de 2017, disponible en: https://www.maastrichtuniversity.nl/blog/2017/10/catalonia-way-forward-comparative-constitutionalrather-international-legal-argument [Consultada 10 de agosto de 2018].

46 Véase, en ese sentido, la afirmación realizada por Robert Muharremi: "Therefore, since there is no rule of international law, which prohibits a declaration of independence, one could argue that there is also no norm of international law, which prohibits secessions". ("Por consiguiente, en tanto no existe una norma de derecho internacional que prohíba una declaración de independencia, se podría argumentar que tampoco existe una norma de derecho internacional que prohíba las secesiones”). Muharremi, “A Note on the ICJ Advisory Opinion...”, p. 880. Véase también, la crítica a la Opinión Consultiva sobre Kosovo manifestada por Anne Peters: "The Kosovo AO can be read both ways: either secession is outside international law in the sense that international law is simply neutral vis-a-vis secession, or international law allows secession". ("La OC de Kosovo puede ser leída en ambos sentidos: bien la secesión está fuera del derecho internacional en el sentido de que el derecho internacional es simplemente neutral respecto a la secesión, o bien el derecho internacional

Número de página no utilizable para citar 
En su Opinión Consultiva sobre Kosovo, de 22 de julio de 2010, la CIJ habría evitado pronunciarse respecto a los efectos jurídicos de la DUI de Kosovo de 17 de febrero de 2008. En efecto, la CIJ se limitó a admitir la conformidad de la DUI con el derecho internacional general, manifestando -en aplicación del principio Lotus- que éste no contiene ninguna prohibición aplicable a las $\mathrm{DUI}^{47}$. Por consiguiente, sería posible afirmar que el pueblo kosovar, al margen de si tenía o no derecho a la libre determinación, no habría cometido ningún hecho internacionalmente ilícito al declarar la DUI; por tanto, un sector de la doctrina sostiene lo mismo respecto de la declaración efectuada por el Parlamento de Cataluña en octubre pasado ${ }^{48}$.

Adicionalmente, la CIJ declaró que el alcance del principio de integridad territorial de los Estados se circunscribe únicamente a la esfera de las relaciones entre Estados ${ }^{49}$. Por consiguiente, no sería aplicable a las relaciones intraestatales y no podría ser aplicado al caso concreto de la DUI de Kosovo $^{50}$.

Como se comentó precedentemente, la CIJ no se pronunció acerca de las consecuencias jurídicas de la DUI, que era lo realmente importante. Probablemente, en virtud de que, como afirma Marcelo Kohen, se trataba de una simple declaración de intención ${ }^{51}$. En consecuencia, es posible distinguir, al igual que Robert Muharremi, entre "declarar" y "efectuar" la independencia ("Distinction Between 'Declaring' and 'Effecting' Independence") ${ }^{52}$.

permite la secesión”), Peters, “Does Kosovo Lie...”, p. 101. Véase además, el análisis de Marc Weller: “[...] as a matter of law, rather than policy preference, the international system is neutral on the question of secession. [Quebec Reference, para 140]". ("[...] en cuestión de derecho, en lugar de preferencia en política externa/interna, el sistema internacional es neutral respecto a la cuestión de la secesión.”); Weller, Marc, "Secession and Self-determination in Western Europe: The Case of Catalonia", en EJIL Talk, 18 de octubre de 2017, disponible en: https://www.ejiltalk.org/secession-and-selfdetermination-in-western-europe-the-case-of-catalonia/[Consultada 10 de Agosto de 2018].

47 CIJ, "Opinión Consultiva... Kosovo", párrs. 79 y ss.

48 Véase, por ejemplo, Verhelst, Anne, "Remedial Secession for Economic Harm in International Law: the Catalan Case", Leuven Centre for Global Governance Studies, Working Paper No. 202, Lovaina, mayo de 2018, p. 20, disponible en: https://ghum.kuleuven.be/ggs/publications/working_papers/2018/202verhelst.

49 CIJ, "Opinión Consultiva... Kosovo", párr. 80.

50 Las críticas de cierto sector de la doctrina se deberían a una interpretación demasiado literal y restrictiva de ciertos artículos o párrafos comprendidos en algunos instrumentos internacionales (e.g., Artículos 1.2 y 2.4 de la Carta de las Naciones Unidas, de 26 de junio de 1945; Artículos 2 y 6 de la Resolución 1514 de la Asamblea General, de 4 de diciembre de 1960; Artículo 1.1 del Pacto Internacional De Derechos Civiles y Políticos, 16 diciembre de 1966; Resolución 2625 de la Asamblea General, 24 de octubre de 1970; Artículos II, IV y VIII del Acta Final de Helsinki, 1 de agosto de 1975; y, Resolución 50/6 de la Asamblea General, 9 de noviembre de 1995). Es posible argüir que, con anterioridad a la Opinión Consultiva sobre Kosovo, el derecho internacional general habría dejado inferir que el principio de integridad territorial constituía un límite del ejercicio del derecho de libre determinación de los pueblos. Véase, por ejemplo, Brilmayer, Lea, "Secession and Self-Determination: A Territorial Interpretation", en Yale Law School Faculty Scholarship Series, Paper 2434, 1991, disponible en: http://digitalcommons.law.yale.edu/cgi/viewcontent.cgi?article=3429\&context=fss_papers. Sin embargo, la doctrina internacionalista más reputada, al comentar la Resolución 2775 E (XXVI) de la Asamblea General, de 29 de noviembre de 1971, ya explicaba lo siguiente: “The principle of 'territorial integrity' does not provide a permanent guarantee of present territorial divisions, nor does it preclude the granting of independence to part of its territory, even where such a grant is contrary to the wishes of the majority of the people of the State as a whole", Crawford, James R., "The Creation of States in International Law", (Oxford: Oxford University Press, 1979), Cap. 8:(3)(iii) "The Status of the bantustans under international law", pp. 341-345.

51 Kohen, "Pour le droit international...".

52 Muharremi, “A Note on the ICJ Advisory Opinion...", pp. 873 y ss. 
En efecto, la CIJ evitó abordar la cuestión relativa a los efectos jurídicos de una DUI, recordando que el acto de declarar la independencia no necesariamente tiene como consecuencia la creación de un nuevo Estado. En efecto, el "statehood” (i.e., estatalidad o calidad de Estado) depende de otras consideraciones. En la actualidad, los criterios comúnmente aceptados para la constitución de un Estado son: (1) Territorio definido o específico; (2) Población; (3) Gobierno; (4) Independencia; y (5) Efectividad ${ }^{53}$. Sin embargo, los requisitos tradicionales establecidos en la "Convención sobre derechos y deberes de los estados" (“Convención de Montevideo”) son: (1) Población permanente; (2) Territorio determinado; (3) Gobierno; y, (4) Capacidad de entrar en relaciones con los demás Estados ${ }^{54}$.

Adicionalmente a los anteriores criterios, actualmente se considera que, a efectos de que una nueva entidad sea considerada un Estado, esta debe cumplir con los estándares de respeto a los derechos humanos y al principio de autodeterminación ${ }^{55}$. En particular, cabe destacar, en relación al proceso de secesión, que en tanto un acto violatorio de una norma imperativa (ius cogens) de derecho internacional es internacionalmente ilícito y, por consiguiente, nulo de pleno derecho; en relación a la creación de Estados, existe la obligación de no reconocer tales hechos internacionalmente ilícitos, en virtud del derecho consuetudinario internacional y de conformidad con los principios generales del derecho, lo cual habría sido confirmado mediante la codificación del proyecto de artículos sobre la responsabilidad del Estado por hechos internacionalmente ilícitos ${ }^{56}$.

En consecuencia, las resoluciones del Consejo de Seguridad y la Asamblea General son -desde una perspectiva jurisprudencial- declaratorias en el sentido de que confirman el deber de los Estados de no reconocer tales situaciones. En términos prácticos, esas resoluciones son esenciales, por cuanto comportan una determinación colectiva de ilegalidad y nulidad ${ }^{57}$. De conformidad con esta doctrina, las Naciones Unidas habrían llevado a los Estados a no reconocer a entidades emergentes creadas sobre la base de actos de agresión (e.g., la República Turca del Norte de Chipre), de discriminación racial sistemática y negación de los derechos

53 Véase, por ejemplo, Crawford, “The Creation of States...", pp. 37-95; Remiro Brotóns, Antonio et al, "Derecho internacional" (Tirant lo Blanch: Valencia, 2007), pp. 97-101.

54 Convención sobre Derechos y Deberes de los Estados, firmada en la Séptima Conferencia Internacional Americana, en Montevideo, Uruguay, el 26 de diciembre de 1933.- "Artículo 1.- El Estado como persona de Derecho Internacional debe reunir los siguientes requisitos: (1) Población permanente; (2) Territorio determinado; (3) Gobierno; y (4) Capacidad de entrar en relaciones con los demás Estados".

55 Ello se habría visto confirmado con la promulgación de las Líneas directrices sobre el reconocimiento de nuevos estados en Europa del Este y en la Unión Soviética1 (16 de diciembre de 1991). En ese sentido, Dugard, John y David Raic, “The role of recognition in the law and practice of secession", en Marcelo Gustavo Kohen (editor), Secession: International Law Perspectives, (Cambridge: Cambridge University Press, 2006), p. 96.

56 Dugard y Raic, "The role of recognition...", p. 101. Cf. Artículos 40 y 41 del Capítulo III, relativo a "Violaciones graves de obligaciones emanadas de normas imperativas del derecho internacional general", del proyecto de artículos sobre la responsabilidad del Estado por hechos internacionalmente ilícitos (AG/56/83). Véase también, el comentario al Artículo 41(2): "Informe de la Comisión de Derecho Internacional", 53 sesión, G.A.O.R. 50 sesión, Suplemento No. 10 (A/56/10), pp. 286-289.

57 Ello tendría su origen en la doctrina del no-reconocimiento, la cual se fundó en el principio ex injuria jus non oritur, según el cual los hechos ilícitos no pueden crear derecho. 
humanos (e.g., los Estados Bantustanes de Sudáfrica) o contrarios al principio de autodeterminación de los pueblos (e.g., Katanga y Rodesia) ${ }^{58}$.

Cabe señalar que existen dos teorías acerca del reconocimiento de un Estado, la teoría constitutiva y la declarativa ${ }^{59}$. La primera entiende el reconocimiento como un acto necesario antes de que la entidad reconocida pueda disfrutar de una personalidad internacional, mientras que la segunda lo ve como un acto político que reconoce un -estatus o- estado de cosas preexistente $^{60}$. Sin embargo, la perspectiva constitutiva tendría una gran deficiencia: no proporciona ninguna respuesta ante el escenario en el cual una entidad emergente recibe el reconocimiento de algunos Estados pero no de otros, lo cual significaría que la nueva entidad tiene y no tiene -al mismo tiempo- una personalidad internacional ${ }^{61}$. Debido a este problema o contradicción, la doctrina mayoritaria opina que el reconocimiento tendría efecto declarativo ${ }^{62}$.

Sin embargo, cabe recordar que inicialmente tan solo se consideraban los requisitos de población y territorio sujetos a un Gobierno, como es posible apreciar en el laudo dictado en el caso Deutsche Continental Gas-Gesellschaft v. État polonais, de 192963. Tales criterios fueron reiterados en otros laudos arbitrales, como por ejemplo, en Arbitration Commission of the International Conference on Yugoslavia (Badinter Arbitration Commission) ${ }^{64}$. Asimismo, cabe recordar la concepción clásica del Estado, por lo que conviene citar a Andrés Bello: "Una nación o Estado es una sociedad de hombres que tiene por objeto la conservación y felicidad de los asociados; que se gobierna por leyes positivas emanadas de ella misma, y es dueño de una porción de territorio" 65 .

Cabe precisar que en el siglo XIX el reconocimiento de un Estado resultaba crucial para su admisión a la "sociedad civilizada" por cuanto el derecho internacional era concebido como el derecho existente entre las "naciones civilizadas" "66 sin importar cómo un pueblo llegaba a

58 Dugard y Raic, “The role of recognition...”, p. 101.

59 La teoría declaratoria fue adoptada en las opiniones de Badinter y confirmada en pronunciamientos consecutivos. Badinter Commission, Opinión 11, en Caplan, R., "Europe and the Recognition of New States in Yugoslavia" (Cambridge: Cambridge University Press, 2005), p. 240.

60 Vidmar, Jure, "Explaining the Legal Effects of Recognition”, en International and Comparative Law Quarterly, 2010, pp. 361362.

61 Vidmar, Jure, "States, Governments, and Collective Recognition", en Chinese (Taiwan) Yearbook of International Law and Affairs, 2015, pp. 136-138. Véase, la crítica original y calificación de "espectáculo grotesco" ("grotesque spectacle"), Lauterpacht, Hersch, "Recognition in International Law" (Cambridge: Cambridge University Press, 1947), p. 78.

62 Harris, D., "Cases and Materials on International Law" (London: Sweet \& Maxwell, 2010), p. 131.

63 Deutsche Continental Gas-Gesellschaft v. État polonais, Laudo de 1 de agosto de 1929, IX Recueil des Décisions des Tribunaux Arbitrales Mixtes, 1930, p. 344.

64 Arbitration Commission of the International Conference on Yugoslavia (Badinter Arbitration Commission), Primera Opinión adoptada el 29 de noviembre de 1991, en cuyo punto (b) estableció : "the state is commonly defined as a community which consists of a territory and a population subject to an organized political authority" véase 31 ILM 1494 (1992).

65 Bello, Andrés, "Principios de Derecho de Jentes" (Imprenta de la Opinión: Santiago de Chile, 1832), Parte Primera, Cap. $1^{\circ}, \$ 1$, p. 10.

66 En ese sentido, Vásquez de Menchaca afirmaba que el Derecho de Gentes tiene instituciones universales pero que es determinado por la práctica de las "naciones civilizadas", así afecte a las demás naciones no civilizadas. Vásquez de Menchaca, Fernando, "Controversiarum illustrium aliarumque usu frequentium”, 1985, Tomo IV, p.424; citado por Abanto, Walter, "La Escuela de Salamanca y su influencia en la formación del Derecho de Gentes", en Pólemos, Derecho \& Sociedad, Lima, 20 de febrero de 2018, disponible en: http://polemos.pe/la-escuela-salamanca-influencia-la-formaciondel-derecho-gentes/\#_ftnref3. 
constituirse en Estado ${ }^{67}$. No obstante, actualmente se considera que el reconocimiento por parte de otros Estados no es propiamente constitutivo de un Estado, sino declarativo en naturaleza y efecto $^{68}$.

Sin embargo, si bien un Estado puede existir a pesar de las reacciones negativas, incluyendo condenas radicales de terceros Estados; en la práctica, un reconocimiento generalizado pareciera ser particularmente valioso desde la perspectiva de aquellas entidades que afirman cumplir los criterios de estatalidad $^{69}$. En consecuencia, la mayoría de partidarios de la teoría declarativa se ven obligados a reconocer al menos algo de reconocimiento de la parte de Estados prexistentes como precondición para acceder al estatus de Estado (“statehood") ${ }^{70}$.

En relación con el eventual reconocimiento de un Estado por parte de un escaso número de países, cabe recordar, como explica James Crawford, que: "Incluso los actos individuales de reconocimiento pueden contribuir a la consolidación del estatus [de Estado]; en términos de Charpentier, el reconocimiento puede hacer que la nueva situación sea oponible al Estado que reconoce [el nuevo Estado]"71.

A este respecto, es importante precisar que, en el supuesto de entidades que no califiquen como Estado por incumplir alguna de los criterios tradicionales de "statehood", el reconocimiento puede ser constitutivo de una obligación legal para el Estado aquiescente. De cualquier forma, como se explicó anteriormente, el acto de reconocimiento sería en principio declarativo, a pesar de que pueda ser de gran importancia en ciertos $\operatorname{casos}^{72}$.

Véase también, una herencia del pensamiento de la Escuela de Salamanca, en el enunciado del artículo 38 numeral 1 literal c) del Estatuto de la Corte Internacional de Justicia: "Artículo 38.- 1. La Corte, cuya función es decidir conforme a derecho internacional las controversias que le sean sometidas, deberá aplicar: (...) c. los principios generales de derecho reconocidos por las naciones civilizadas; (...)”. (Énfasis agregado).

67 Crawford, James, "The Criteria for Statehood in International Law", en The British Yearbook of International Law, Vol. 48, Issue 1, 1 enero 1977, pp. 93-182, especialmente p. 98, disponible en: https://www.ilsa.org/jessup/jessup13/British\%20Yearbook\%20of\%20International\%20Law-1977-Crawford-93-182.pdf [Consultada 10 de agosto de 2018].

68 En ese sentido, Crawford, "The Creation of States...", pp. 27-28 y 92-93; Harris, "Cases and materials...", pp. 144-145, quien cita a James Leslie Brierly, "The Law of Nations: An Introduction to the Role of International Law in International Relations" (Clarendon Press: Oxford, 1963), 6 Ed., pp. 138-139.

69 Almqvist, Jessica, "The Politics of Recognition, Kosovo and International Law" (Real Instituto Elcano: Madrid, 2009), Working Paper 14/2009, 16 de marzo de 2009, pp. 5-6, disponible en:

http://www.realinstitutoelcano.org/wps/wcm/connect/59fc54004f018b9cbaacfe3170baead1/WP-

14_Almqvist_Kosovo_International_Law.pdf?MOD=AJPERES\&CACHEID=59fc54004f018b9cbaacfe3170baead1.

70 Crawford, "The Creation of States...", p. 74.

71 "Even individual acts of recognition may contribute towards the consolidation of status; in Charpentier's terms, recognition may render the new situation opposable to the recognizing State". ("Incluso los actos individuales de reconocimiento pueden contribuir a la consolidación de la condición de Estado; en términos de Charpentier, el reconocimiento puede hacer que la nueva situación sea oponible al Estado que lo reconoce"). Crawford, "The Creation of States...”, p. 27; quien cita a Charpentier, Jean, "La reconnaissance internationale et l'évolution du droit des gens" (Éditions Pedone: París, 1956), pp. 217-225.

72 Crawford, “The Creation of States...", p. 92. Cabe apuntar que, en ciertas ocasiones, el término "reconocimiento" puede ser usado para describir actos propiamente constitutivos de un Estado en particular (e.g., un tratado multilateral que establece un nuevo Estado); pp. 27-28.

Número de página no utilizable para citar 
El reconocimiento por parte de terceros Estados podría ser determinante, por cuanto, como la Corte Suprema de Canadá manifestó en su pronunciamiento, de 20 de agosto de 1998, relativo a la secesión de Quebec, el éxito definitivo de una secesión unilateral dependería del reconocimiento de la comunidad internacional ${ }^{73}$. Sin embargo, también podría no serlo, en virtud a que una comunidad que dice ser soberana pero no puede ejercer este derecho o atributo en la práctica, no es un Estado propiamente dicho ${ }^{74}$.

No obstante lo referido al reconocimiento, es esencial apreciar que las consideraciones políticas influyen en la decisión de otorgarlo y pueden impulsar a un Estado a reconocer prematuramente a una entidad emergente o a negarse a otorgarle reconocimiento. La naturaleza política del reconocimiento habría favorecido la aceptación de la teoría declarativa ${ }^{75}$, según la cual una entidad que cumpla con los requisitos de "statehood" se convierte en un Estado independientemente del reconocimiento ${ }^{76}$.

La teoría declarativa podría ser adecuada en el caso de un Estado que ha sido reconocido por algunos Estados pero no por otros; sin embargo, es difícil sostener que una entidad que ha recibido reconocimiento por ninguno o muy pocos Estados, como los casos de la República Turca del Norte de Chipre o los Estados Bantustanes de Sudáfrica (Transkei, Bofutatsuana, Venda o Ciskei), puede pretender ser un Estado, por cuanto no puede demostrar su capacidad para entablar relaciones con otros Estados y, por consiguiente, desde un punto de vista funcional -de cumplimiento de los criterios tradicionales- no puede describirse como un Estado ${ }^{77}$.

En relación con el caso kosovar, ciertos autores opinan que lo más conveniente para la CIJ, habría sido aplicar la denominada cláusula de salvaguardia contenida en la Resolución 2625 (XXV) de la $\mathrm{AGNU}^{78}$, debido a que el contexto de graves violaciones -sistemáticas y masivas-

73 Supreme Court of Canada, "Reference by the Governor...", párr. 155. Cabe precisar que, en la Opinión Consultiva sobre Kosovo, tanto los Estados participantes -en los procedimientos- como la CIJ hacen referencia a este pronunciamiento de la Corte Suprema de Canadá. CIJ, "Opinión Consultiva... Kosovo”, párrs. 55-56.

Cabe precisar que, en la Opinión Consultiva sobre Kosovo, tanto los Estados participantes -en los procedimientoscomo la CIJ hacen referencia a este pronunciamiento de la Corte Suprema de Canadá. CIJ, "Opinión Consultiva... Kosovo”, párrs. 55-56.

74 Bull, Hedley, "The Anarchical Society: A Study of Order in World Politics" (London: Macmillan, 1977), p.8; citado por Dugard y Raic, “The role of recognition...", p. 99.

75 La doctrina declarativa tendría como origen las Opiniones de la Comisión de arbitraje de la conferencia sobre Yugoslavia (Comité de Arbitraje de Badinter), en las cuales se determinó que la existencia o desaparición del Estado es una cuestión de hecho y que los efectos del reconocimiento por parte de otros Estados son puramente declaratorios ("the existence or disappearance of the State is a question of fact; that the effects of recognition by other States are purely declaratory"). Opinión 1 in ILR 92, p. 162.

76 Adicionalmente, la naturaleza política del reconocimiento podría asimismo explicar la actitud anti-secesionista de los órganos políticos de las Naciones Unidas. Véase, en relación con la referida actitud de los órganos políticos de las Naciones Unidas, Nolte, Georg, "Secession and external intervention", en Marcelo G. Kohen (editor), Secession: International Law Perspectives, (Cambridge: Cambridge University Press, 2006), pp. 67-69.

77 En ese sentido, Dugard y Raic, “The role of recognition...", p. 98.

78 Véase, párrafo final de la Resolución 2625 de la AGNU de 24 de octubre de 1970: “(...) Ninguna de las disposiciones de los párrafos precedentes se entenderá en el sentido de que autoriza o fomenta cualquier acción encaminada a quebrantar o menospreciar, total o parcialmente, la integridad territorial de los Estados soberanos e independientes que se conduzcan de conformidad con el principio de la igualdad de derechos y de la libre 
de derechos humanos y discriminaciones contra la población albanokosovar con anterioridad a la Resolución 1244 del CS podría haber justificado la aplicabilidad de esta cláusula. Tales autores sostienen que, de haber fundamentado la Opinión Consultiva sobre Kosovo en la aplicación de la cláusula de salvaguardia, la CIJ no habría necesitado insistir en el carácter excepcional del caso, por cuanto la referida cláusula comporta per se una excepción a la regla.

En todo caso, es posible reconocer un supuesto adicional de ejercicio a la libre determinación, cuyos fundamentos se encuentran en las propias resoluciones de Naciones Unidas y que ha sido objeto de un vasto desarrollo doctrinal: la "secesión como remedio" ("remedial secession"). Incluso, hay quienes llegan a afirmar que la Opinión Consultiva sobre Kosovo supone una aceptación implícita de esta causal excepcional de ejercicio del derecho a la libre determinación ${ }^{79}$. Sin embargo, como se explicó precedentemente, la situación del pueblo kosovar en 2008 había cambiado sustancialmente en comparación al periodo de grave crisis humanitaria sufrido entre 1996 y 1999.

\section{Nuevos supuestos de autodeterminación}

En relación con el consentimiento del Estado matriz o predecesor, cabe destacar que durante los últimos años varios Estados han declarado su independencia con el consentimiento del Estado predecesor, aunque a regañadientes después de una negativa inicial. Estos incluyen Eslovenia en 1991, Timor Oriental en 2002 y Sudán del Sur en 2011, cuando los resultados de un referéndum de independencia finalmente fueron aceptados por el estado predecesor. De

determinación de los pueblos antes descritos y estén, por tanto, dotados de un gobierno que represente a la totalidad del pueblo perteneciente al territorio, sin distinción por motivo de raza, credo o color".

79 Véase, por ejemplo, Valderrama Escobar, Marco Antonio, "La Opinión Consultiva de la Corte Internacional de Justicia sobre la declaración unilateral de independencia con respecto A Kosovo" (Universidad de Chile: Santiago de Chile, 2013), disponible en: http://repositorio.uchile.cl/bitstream/handle/2250/113911/de-

valderrama_m.pdf?sequence=1\&isAllowed $=$ y. Véase, sobre la formación de una costumbre internacional, Hillestad, Aksel Erik, “A Right to Remedial Secession?”: The Case of Kosovo and its Implications for International Law”, Universidad de Oslo, Tesis de Maestría, 2010, pp. 22 y ss., disponible en:

https://www.duo.uio.no/bitstream/handle/10852/18802/101564.pdf?sequence=1\&isAllowed=y. Véase además, Meller, Samuel E., "The Kosovo case: an argument for a Remedial declaration of Independence", en Georgia Journal of International and Comparative Law, Vol. 40, 2012, pp. 865-866, disponible en:

http://digitalcommons.law.uga.edu/cgi/viewcontent.cgi?article=1007\&context=gjicl; quien explica la falta de pronunciamiento respecto de si se trataba efectivamente de un caso de secesión moderna en virtud de la necesidad de no contrariar el principio Lotus y dejar que el principio de efectividad rija la DUI de Kosovo y los actos políticos posteriores. 
manera similar, Checoslovaquia se separó pacíficamente en la República Checa ${ }^{80}$ y Eslovaquia en 1993 con el acuerdo de ambas regiones ${ }^{81}$.

Si bien el acuerdo del Estado predecesor supone la situación ideal en el derecho internacional; en la práctica, la mayoría de secesiones no se producen con el consentimiento del Estado predecesor. Existe una gran cantidad de ejemplos de lo anterior: Armenia ${ }^{82}$, Azerbaiyán ${ }^{83}$, Bielorrusia $^{84}$, Croacia ${ }^{85}$, Georgia ${ }^{86}$, Letonia $^{87}$, Macedonia ${ }^{88}$, Ucrania ${ }^{89}$, Turkmenistán ${ }^{90}$, Uzbekistán $^{91}$, Bosnia y Herzegovina ${ }^{92}$, etc. En la mayoría de casos, un referéndum fue realizado previamente, o para avalar el proceso secesionista. En definitiva, entre todas las herramientas de democracia participativa, el referéndum ha demostrado ser la que otorga más legitimidad ${ }^{93}$.

Sin embargo, más allá de tendencias, surge la pregunta fundamental acerca de si el consentimiento del Estado matriz o predecesor es realmente esencial cuando un pueblo va a

80 A este respecto, cabe comentar que después de un debate interno sobre su falta de reconocimiento internacional, República Checa cambió oficialmente su nombre a "Cz̨ecbia", más de dos décadas después de su independencia. Taylor, Adam, "What nine countries founded in past 25 years teach Catalonia?", en Dawn, 1 de octubre de 2017, disponible en: https://www.dawn.com/news/1361066.

81 Similar separación, aunque de una unión personal en este caso, comportó la disolución de la unión entre Noruega y Suecia, conocida como Reinos Unidos de Suecia y Noruega, en 1905.

82 Armenia llevó a cabo un referéndum el 21 de septiembre de 1991 sin el consentimiento de la Unión Soviética y fue admitido como miembro de las Naciones Unidas el 2 de marzo de 1992.

83 Azerbaiyán llevó a cabo un referéndum el 29 de diciembre de 1991 sin el consentimiento de la Unión Soviética y fue admitido como miembro de las Naciones Unidas el 2 de marzo de 1992.

84 Bielorrusia declaró su independencia sin el consentimiento de la Unión Soviética el 29 de diciembre de 1991, consiguió su independencia el 26 de diciembre de 1991 y fue reconocido por todos los miembros de la Unión Europea.

85 Croacia llevó a cabo un referéndum el 19 de mayo de 1991 sin el consentimiento de Yugoslavia, declaró su independencia el 15 de junio de 1991 y fue admitido como miembro de las Naciones Unidas el 5 de mayo de 1992.

86 Georgia llevó a cabo un referéndum el 31 de marzo de 1991 sin el consentimiento de la Unión Soviética y fue admitido como miembro de las Naciones Unidas el 31 de julio de 1992.

87 Letonia llevó a cabo un referéndum el 3 de marzo de 1991 sin el consentimiento de la Unión Soviética y fue admitido como miembro de las Naciones Unidas el 17 de septiembre de 1991.

88 Macedonia llevó a cabo un referéndum el 8 de septiembre de1991 sin el consentimiento de Yugoslavia, declaró su independencia el 20 de noviembre de 1991 y fue admitido como miembro de las Naciones Unidas el 8 de abril de 1993.

89 Ucrania llevó a cabo un referéndum el 1 de diciembre de 1991 sin el consentimiento de la Unión Soviética y fue reconocido por todos los miembros de la Unión Europea.

90 Turkmenistán llevó a cabo un referéndum el 26 de octubre de 1991 sin el consentimiento de la Unión Soviética y fue admitido como miembro de las Naciones Unidas el 2 de marzo de 1992.

91 Uzbekistán llevó a cabo un referéndum el 29 de diciembre de 1991 sin el consentimiento de la Unión Soviética y fue admitido como miembro de las Naciones Unidas el 2 de marzo de 1992.

92 Bosnia y Herzegovina llevó a cabo un referéndum el 29 de febrero de 1992 y el 1 de marzo de 1992 sin el consentimiento de Yugoslavia, declaró su independencia el 1 de marzo de 1992 y fue admitido como miembro de las Naciones Unidas el 22 de mayo de 1992.

93 Véase, sobre una diferenciación entre legalidad y legitimidad en relación con el referéndum, Saint Clair, Frédéric, "Crise catalane: entre légalité et légitimité", en Le Figaro, 2 de noviembre de 2017, disponible en: http://www.lefigaro.fr/vox/monde/2017/11/02/31002-20171102ARTFIG00234-crise-catalane-entre-legalite-etlegitimite.php. Cabe comentar que en el citado artículo se propone un referéndum nacional español que revalide un eventual resultado en favor de la independencia en un referéndum a nivel autonómico, en lugar de simplemente denegar la realización de la herramienta de democracia participativa que reviste de mayor legitimidad a un proceso de expresión de la voluntad popular, al margen del principio de legalidad. Véase también, Rocher, François, "La incidencia democrática de la nebulosa obligación de claridad del Dictamen relativo a la secesión del Quebec", en Eunomía n 13, octubre 2017 - marzo 2018, p. 37, disponible en: https://e-revistas.uc3m.es/index.php/EUNOM/article/view/3804: "[...] la sola legalidad no es, en sí misma, suficiente y debe conformarse a un conjunto de principios, de ideas o de valores que conformen una justificación moral de la ley o del reglamento. Es sobre esta base que se apoya en el consentimiento, fundamento de la legitimidad". 
declarar su independencia. La respuesta aparentemente debería ser no, por cuanto argüir lo contrario resulta contradictorio en una democracia constitucional, contrariando incluso la práctica internacional $^{94}$.

La práctica internacional igualmente demuestra que, no obstante acontece en la minoría de situaciones, la "secesión pactada" siempre comporta una alternativa a tener en cuenta. La secesión pacífica es sin duda la vía idónea, mientras que las desintegraciones sangrientas son para todos indeseables. Como se comentó precedentemente, el caso de Sudán del Sur es un caso excepcional de "secesión pactada", a pesar de haberse librado una cruenta guerra civil.

Un ejemplo más pacífico lo comporta la independencia lograda por Surinam sobre Holanda en 1975. De igual manera, es posible mencionar la secesión de Eritrea con el consentimiento de Etiopía en 1993, o la de Montenegro con el acuerdo de Serbia en 2006 ${ }^{95}$. En un futuro cercano, éste también podría ser el caso de Escocia o de Nueva Caledonia, de ganar la opción independentista en sus correspondientes referéndums.

A este respecto, cabe destacar la secesión por parte de Bangladés de Pakistán en 1971, aunque este último reconociera la independencia del primero recién después de dos años de acontecida la secesión. Este caso reviste especial importancia en virtud de indicar cierta tolerancia por parte de la comunidad internacional hacia la autodeterminación moderna, fuera del contexto colonial ${ }^{96}$.

Por otra parte, en la Opinión (“Avis”) relativa a la secesión de Quebec de 20 de agosto de 1998, la Corte Suprema de Canadá determinó su dictamen sobre la base de cuatro principios constitucionales subyacentes: el federal, el democrático, el constitucional y el Estado de Derecho y el de respeto a los derechos de las minorías; los cuales deben ser interpretados y aplicados en simbiosis entre éstos. En efecto, la Corte Suprema de Canadá destacó que "ninguno de estos principios puede ser definido en abstracción de los otros y ninguno de estos principios puede impedir o excluir la aplicación de ninguno de los demás"97.

El pronunciamiento relativo a la secesión de Quebec reconoce cuatro principios constitucionales subyacentes que inspiran el texto de la Constitución, comportando premisas implícitas. De esta manera, la Constitución conforma un conjunto de normas jurídicas pero también un marco de principios implícitos $^{98}$. La Corte Suprema de Canadá, a falta una disposición expresa que permita a una de sus unidades territoriales constitutivas llevar a cabo una secesión mediante un proceso

94 En ese sentido, The Conversation, "Self-determination is legal under international law - it's hypocritical to argue otherwise for Catalonia”, 30 de octubre de 2017, disponible en: http:// theconversation.com/self-determination-is-legal-underinternational-law-its-hypocritical-to-argue-otherwise-for-catalonia-86558 [Consultada 10 de Agosto de 2018].

95 En el caso de la secesión de Serbia por parte de Montenegro, el reconocimiento de este último por parte del primero (15 de junio de 2006), se dio tan solo días después de proclamada la independencia (3 de junio de 2006).

96 Shany, Y., "Does International Law Grant the People of Crimea and Donetsk a Right to Secede? Revisiting Self Determination in Light of the 2014 Events in Ukraine", en Brown Journal of World Affairs, 2014-15, n 1, p. 240.

97 Rocher, "La incidencia democrática...", pp. 31-60, especialmente p. 33.

98 Supreme Court of Canada, "Reference by the Governor...", párr. 36. 
previamente definido, determinó que la Constitución no es un obstáculo y que el principio constitucional subyacente significa que la democracia no permite a las autoridades políticas ignorar la voluntad de modificación constitucional, debiendo acceder al diálogo para tal efecto ${ }^{99}$.

Adicionalmente, en el caso de la secesión de Quebec, la Corte Suprema de Canadá señaló que, en una democracia constitucional, los deseos de las mayorías deben ser respetados por cuanto ninguna mayoría es más legítima que otra como expresión de la opinión democrática ${ }^{100}$, aunque finalmente determinó que Quebec no podía pretender ejercer el derecho a la autodeterminación mediante la secesión (i.e., a nivel externo), por cuanto los quebequenses no se encontraban impedidos del ejercicio de su derecho a la autodeterminación o autonomía a nivel interno ${ }^{101}$.

De esta manera, la Corte Suprema de Canadá se alineó a lo establecido por el Comité Internacional de Juristas en el Informe en el caso de las Islas Áland (Finlandia) de 1920, en el cual se determinó que el pueblo alandés únicamente tendría derecho a la secesión en caso Finlandia no respetase su autonomía étnica y cultural, situación distante a la del caso alandés, incluso en ese entonces ${ }^{102}$.

En el caso del pueblo kurdo, por ejemplo, se afirma que si su derecho a la autonomía interna no fuera respetado, éste podría legítimamente optar por la secesión; sin embargo, en caso su autonomía sea respetada a nivel interno, la eventual relación autonómica deberá regirse por el derecho interno de $\operatorname{Iraq}^{103}$.

A este respecto, es preciso exponer el significado del concepto de autonomía interna. Según Stavenhagen, la autonomía interna afectaría no a la propia soberanía del Estado, sino a "[...] la forma de organización política y económica interna”. Por tanto, “[...] más que de secesión o independencia política, se habla hoy en día de diversas formas de autonomía política, territorial y económica" ${ }^{\prime 104}$. En consecuencia, en una democracia constitucional debe haber un proceso continuo de discusión - por lo menos en los ámbitos político y económico- dado que nadie tiene el monopolio de la verdad. Construir mayorías requiere compromiso, negociación y deliberación; por tanto, un sistema pluralista democrático debe tomar en consideración las inevitables opiniones discrepantes e intentar incorporarlas en el ordenamiento jurídico ${ }^{105}$.

\footnotetext{
99 Supreme Court of Canada, "Reference by the Governor...", párr. 42.

100 Supreme Court of Canada, "Reference by the Governor...", párr. 66.

101 Supreme Court of Canada, "Reference by the Governor...", párrs. 134-136.

102 Sociedad de las Naciones, "Report: Of the International Committee of Jurists entrusted by the Council of the League of Nations with the task of giving an advisory opinion upon the legal aspects of the Aaland Islands question", Report of the International Committee of Jurists, Aaland Islands Report, Advisory Opinion, League of Nations Official Journal, octubre de 1920, disponible en: https://www.ilsa.org/jessup/jessup10/basicmats/aaland1.pdf [Consultada 10 de agosto de 2018].

103 Sterio, Milena, "Do Kurds Have the Right to Self-Determination and/or Secession?".

104 Stavenhagen, Rodolfo. "Los derechos indígenas: algunos problemas conceptuales". Conferencia impartida en el programa de Doctorado "Relaciones Interétnicas en América Latina: Pasado y Presente", Universidad Internacional de Andalucía (Huelva: La Rábida, 1998), citado por Cabedo Mallol, Vicente, "Constituciones, Derecho y Justicia en los Pueblos Indígenas de América Latina” (Lima: Editorial PUCP, 2002), pp. 53-54.

105 Supreme Court of Canada, "Reference by the Governor...", párr. 68.
} 
El pronunciamiento canadiense tiene especial relevancia en el caso del pueblo catalán, por cuanto el Tribunal Constitucional español citó expresamente, en los fundamentos de su Sentencia de 25 de marzo de 2014, el pronunciamiento de 20 de agosto de 1998 de la Corte Suprema de Canadá ${ }^{106}$. De esta manera, el Tribunal Constitucional español habría abierto la puerta para un diálogo "transconstitucional" 107 , del cual se deduce el deber de negociar de buena $\mathrm{fe}^{108}$. En efecto, en las conclusiones del pronunciamiento de la Corte Suprema de Canadá, es posible identificar la obligación de negociar de buena fe, fundada en los cuatro principios constitucionales subyacentes anteriormente mencionados ${ }^{109}$, los cuales permiten interpretar el texto constitucional. Entre estos principios, cabe destacar, además del referido al respeto a las minorías, el de la democracia constitucional ${ }^{110}$.

El Avis relativo a la secesión de Quebec supuso incuestionablemente un punto de inflexión en el proceso soberanista quebequense, al reconocer la capacidad del Quebec de separarse del resto de Canadá toda vez que se cumplieran tres condiciones ${ }^{111}$ : (i) una pregunta clara, (ii) una respuesta clara; $y$, (iii) una negociación previa ${ }^{112}$.

Adicionalmente, es preciso advertir que el entendimiento del principio democrático rebasa el mero marco formal del gobierno representativo y respetuoso del Estado de Derecho. Es por ello que la Corte Suprema de Canadá ha extendido su definición a tres nuevas dimensiones: “(1) la democracia es un estado permanente de deliberación, de discusión, de debate, de expresión de opiniones, de compromisos y de negociaciones; (2) impone la necesidad de tomar en consideración las voces disidentes y de darles respuesta en las leyes; (3) el derecho de proponer modificaciones constitucionales se traduce en la obligación de comprometerse en un debate para

106 Tribunal Constitucional español, Sentencia 42/2014, de 25 de marzo de 2014. Impugnación de disposiciones autonómicas 1389-2013, disponible en: https://www.boe.es/boe/dias/2014/04/10/pdfs/BOE-A-2014-3885.pdf, fundamento jurídico 3 , párr. $5^{\circ}$, p. 19.

107 Por lo que sería conveniente tener en cuenta lo explicado por François Rocher, extrayendo lecciones de la Opinión relativa a la secesión de Quebec: “[...] la sola legalidad no es, en sí misma, suficiente y debe conformarse a un conjunto de principios, de ideas o de valores que conformen una justificación moral de la ley o del reglamento. Es sobre esta base que se apoya en el consentimiento, fundamento de la legitimidad". Rocher, "La incidencia democrática...", p. 37.

108 Extraído del precitado caso de la Secesión de Quebec, Supreme Court of Canada, "Reference by the Governor...”. Véase, en ese sentido, las conclusiones de los profesores Weller, "Secession and Self-determination..."; y, Vidmar, "Catalonia: The Way Forward...".

109 "El proceso de negociación debe ser conducido en base a los principios constitucionales anteriormente descritos, los cuales deben informar las acciones de todos los participantes en el proceso de negociación”, Supreme Court of Canada, "Reference by the Governor...", párr. 94.

110 Rocher, "La incidencia democrática...", p. 44.

111 Guénette, David y Alain-G. Gagnon, "Del referéndum a la secesión - El proceso quebequense de acceso a la soberanía y las lecciones aprendidas con respecto a la autodeterminación”, en Eunomía n 13, octubre 2017 - marzo 2018, p. 22, disponible en: https://erevistas.uc3m.es/index.php/EUNOM/article/view/3803 [Consultada 10 de agosto de 2018].

$112 \mathrm{Al}$ respecto, cabe comentar que, tanto la experiencia referendaria catalana como la escocesa han llevado a Liñeira y Cetrà a establecer cuatro lecciones de utilidad en futuros procesos: (i) el requisito de un mandato popular; (ii) una decisión tomada a través de un referéndum; (iii) un acuerdo entre Estado y sub-Estado para determinar los términos de la consulta; y, (iv) la claridad de la pregunta en cuestión. Harvey, Malcolm, "La experiencia escocesa en los referenda de devolución y secesión $=$ The Scottish experience of devolution and secession referenda", en Eunomía n 13, octubre 2017 - marzo 2018, p. 75; citando a Liñeira, R. y Cetrà, D., "The Independence Case in Comparative Perspective”, en The Political Quarterly, Vol. 86, No. 2, abril de 2015, pp. 257-264, esp. p. 261. 
tomar en consideración la expresión democrática de un deseo de cambio pudiendo ser expresado por una o varias provincias"113.

La actitud abierta a negociar y dialogar con la entidad secesionista, por parte de Canadá, si bien no es consecuencia de ninguna obligación propia del derecho internacional público, muestra en cambio qué esperar de una democracia constitucional ${ }^{114}$. Al imponer la obligación de negociar de buena fe la secesión en respuesta a la expresión de una mayoría clara a favor de esta, la Corte Suprema de Canadá estableció principios fundamentales que constituyen parámetros que deben ser respetados en un sistema de democracia constitucional ${ }^{115}$.

En consecuencia, es posible inferir un último supuesto de ejercicio de derecho a la libre determinación, aportado en este caso por el derecho constitucional comparado, aunque recogido -como se explicó anteriormente ${ }^{116}$ - por la Opinión Consultiva sobre Kosovo, aquel al que puede optar un pueblo impedido $-\mathrm{u}$ obstaculizado- de ejercer su autonomía interna ${ }^{117}$. Por consiguiente, en el marco de un sistema de democracia constitucional, ante la voluntad manifiesta de independencia de una mayoría clara de la población de la correspondiente entidad, debe darse un diálogo entre las "dos mayorías legítimas" ${ }^{118}$, el cual podría generar modificaciones constitucionales o, incluso, una eventual secesión.

\section{Conclusiones}

La necesidad de no contrariar el principio Lotus $^{119}$ y permitir que el principio de efectividad ${ }^{120}$ rija la DUI de Kosovo y los actos políticos posteriores, probablemente fueron las razones que

113 Rocher, "La incidencia democrática...", p. 46.

114 Vidmar, "Catalonia: The Way Forward...".

115 Guénette y Gagnon, "Del referéndum a la secesión...”, pp. 26-27.

116 CIJ, "Opinión Consultiva... Kosovo", párrs. 55-56.

117 Aquellos pueblos que no se encuentran sometidos ni ocupados únicamente tienen derecho a la autodeterminación externa (frente al Estado), si se les niega, impide u obstaculiza el ejercicio del derecho a la autodeterminación interna (dentro del mismo Estado).

118 Supreme Court of Canada, "Reference by the Governor...", párr. 93.

119 Según el principio "Lotus", un hecho es -internacionalmente- lícito de no existir una norma de derecho internacional que lo prohíba. El principio fue establecido por la Corte Permanente de Justicia Internacional en 1927 a propósito del caso S.S. Lotus y ha sido reiterado por la CIJ en subsecuentes fallos, como en el caso "Actividades militares y paramilitares contra el Gobierno de Nicaragua" (Nicaragua c. Estados Unidos) o la Opinión Consultiva sobre la "Legalidad de la amenaza o el empleo de armas nucleares". Mediante la Opinión Consultiva sobre Kosovo, la CIJ habría extendido el referido principio a entidades que podrían ser consideradas Estado en statu nascendi. Muharremi, "A Note on the ICJ Advisory Opinion...".

120 Véase, para un análisis crítico del principio de efectividad, Christakis, Theodore, "The State as a 'primary fact': some thoughts on the principle of effectiveness", en Marcelo G. Kohen (editor), Secession: International Law Perspectives, (Cambridge: Cambridge University Press, 2006), pp. 138-170. Sin embargo, si bien el autor concluye que el exceso de realismo puede ser peligroso, también reconoce que en la hipótesis de un vacío o laguna jurídica queda claro que la efectividad juega un rol importante y que finalmente de los hechos se origina el derecho ("Dans l'hypothese d'un vacuum juris, donc, il est clair que l'effectivite joue un role important et que finalement ex factis ius oritur'), p. 156. 
llevaron a la CIJ a afirmar que en tanto no existiría norma alguna en el derecho internacional general que prohíba las DUI ${ }^{121}$, en principio éstas serían conformes con el derecho internacional general $^{122}$. De igual manera, se podría afirmar que tampoco existe una norma en el derecho internacional que prohíba la secesión ${ }^{123}$; considerando, como sostiene Olivier Corten, que la secesión se encuentra regulada por el derecho nacional, no por el derecho internacional ${ }^{124}$. En ese sentido, la visión tradicional sostenía que los movimientos secesionistas que no se encontraran bajo control extranjero serían puramente un asunto interno. Según esta perspectiva, el derecho internacional ni alentaría el secesionismo ni lo prohibiría; sino que éste sería simplemente una cuestión de hecho ${ }^{125}$.

Sin embargo, lo anterior no debe llevarnos a la ligereza de creer que, en tanto no existiría una norma de derecho internacional general que prohíba la secesión, ésta sería conforme con el mismo, por cuanto un enfoque guiado por la "teoría de la libertad residual" no estaría exento de críticas $^{126}$. Al respecto, es preciso advertir que actualmente se afirma que el derecho internacional regularía cada vez más la secesión; impidiéndola en ciertos casos (cuando viola principios fundamentales), autorizándola en otros (e.g., Eritrea, Estados Bálticos, entre otros) y permitiéndola únicamente para las situaciones restantes ${ }^{127}$.

A este respecto, el Juez Koroma, sostuvo en su opinión disidente de la Opinión Consultiva sobre Kosovo que la afirmación en el sentido de que el derecho internacional ni permite ni prohíbe las DUI sólo tendría sentido si se realiza en abstracto, no en un caso concreto, en el que en función

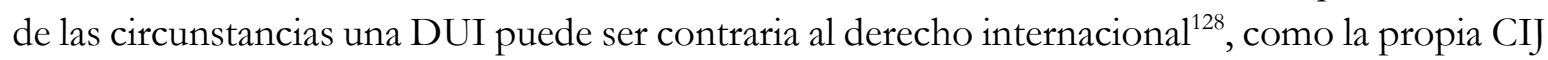

121 En ese sentido, Meller, "The Kosovo case...".

122 Véase, Verhelst, "Remedial Secession...".

123 En ese sentido, Muharremi, "A Note on the ICJ Advisory Opinion...".

124 Corten, Olivier, “Territorial Integrity Narrowly Interpreted: Reasserting the Classical Inter-State Paradigm of International Law', en Leiden Journal of International Law, 2011, pp. 87-88.

125 Kohen, Marcelo, "Introduction”, en Marcelo G. Kohen (editor), Secession: International Law Perspectives, (Cambridge: Cambridge University Press, 2006), p. 5.

126 Véase, por ejemplo, las opiniones disidentes de los Jueces Simma y Koroma. Véase también, la crítica realizada por: Bermejo, Romualdo y Cesáreo Gutiérrez, "La declaración unilateral de independencia de Kosovo a la luz de la opinión consultiva de la Corte Internacional de Justicia de 22 julio de 2010 y de las declaraciones, opiniones individuales y disidentes a la misma", en Anuario español de derecho internacional, Vol. 26, 2010, p. 47: "La Corte, en fin, entiende que la Declaración de independencia de 2008 no viola el Derecho internacional, porque este no contiene norma alguna que prohíba hacer declaraciones de independencia. Así formulada, la frase resulta sorprendente para el internacionalista, por su laconismo, por su elementalidad, por su incuria en el esfuerzo de convencer".

127 Kohen, "Introduction", pp. 19-20. La citada doctrina sostiene que el derecho internacional autorizaría la secesión en tres casos: (i) De territorios incorporados a un Estado por decisión de la AGNU bajo ciertas condiciones que son incumplidas por dicho Estado (e.g., Eritrea); (ii) De entidades ilegalmente incorporadas o anexadas a un Estado del cual deciden separarse (e.g., los Estados Bálticos en 1991); y, (iii) De pueblos a los cuales la legislación nacional interna les reconoce el derecho a la autodeterminación, en cuyo caso el incumplimiento de las normas nacionales pertinentes por parte del gobierno central puede abrir el camino a una secesión legal desde el punto de vista del derecho internacional (e.g., Etiopía, Serbia y Montenegro, San Cristóbal y Nieves, y Uzbekistán).

128 Opinión disidente del Juez Koroma, párr. 20. 
reconoció que ocurrió en anteriores ocasiones (Rhodesia del Sur, Chipre septentrional y de la República Srpska) ${ }^{129}$.

Adicionalmente, la CIJ declaró, a propósito de la DUI del pueblo kosovar, que el alcance del principio de integridad territorial de los Estados se circunscribe únicamente a la esfera de las relaciones entre Estados ${ }^{130}$; por consiguiente, no sería aplicable a las relaciones entre pueblos que aspiran a la libre determinación y el Estado matriz o predecesor. Además, la doctrina más renombrada en derecho internacional general ya entendía, con antelación a la DUI de Kosovo, que el principio de integridad territorial no proporciona una garantía permanente de las divisiones territoriales actuales, ni excluye la concesión de la independencia a parte de su territorio, incluso cuando tal concesión sea contraria a los deseos de la mayoría de las personas del Estado como un todo ${ }^{131}$.

En virtud del Informe en el caso de las Islas Áland ${ }^{132}$, así como de la referencia expresa al pronunciamiento de la Corte Suprema de Canadá en la Opinión Consultiva sobre Kosovo ${ }^{133}$, es posible tener en consideración un último supuesto teórico de ejercicio derecho a la libre determinación, como respuesta a la falta de autonomía interna en una democracia constitucional, con o sin el consentimiento del Estado predecesor. Probablemente, los ejemplos prácticos y recientes, capaces de probar la viabilidad de este último supuesto, en su modalidad unilateral no consentida-, sean las independencias de Eslovenia ${ }^{134}$ y Croacia ${ }^{135}$ en 1991, y su consecuente secesión de la ex Yugoslavia ${ }^{136}$.

129 CIJ, “Opinión Consultiva... Kosovo”, párr. 81.

130 Véase, una visión crítica del principio de integridad territorial, Oklopcic, Zoran, "The Independence of Kosovo: Between Self-Determination, Territorial Rights and Functionality", Carleton University, disponible en: https://seis.bristol.ac.uk/ plcdib/territory/papers/oklopcic_kosovo.pdf.

131 'The principle of 'territorial integrity' does not provide a permanent guarantee of present territorial divisions, nor does it preclude the granting of independence to part of its territory, even where such a grant is contrary to the wishes of the majority of the people of the State as a whole". Crawford, "The Creation of States...", pp. 341-345.

132 Sociedad de las Naciones, "Report: Of the International Committee...".

133 CIJ, "Opinión Consultiva... Kosovo", párrs. 55-56.

134 Véase, al respecto, Hudin, Miquel, "If you must, Catalonia is Slovenia, not Kosovo”, 20 de mayo de 2013, disponible en: https://www.hudin.com/blog/if-you-must-catalonia-is-slovenia-not-kosovo/.

135 A este respecto, cabe recordar que, a fines de la década de 1980, la anulación efectiva de la autonomía constitucional de Kosovo y Vojvodina por parte de Serbia y el establecimiento de un gobierno pro-serbio en Montenegro le dieron a Serbia más poder en el gobierno federal yugoslavo, lo cual le permitió superar a Croacia, Eslovenia y Macedonia en el proceso federal de toma de decisiones. Lo anterior, sumado a la sobrerrepresentación de los serbios en la administración pública federal y en el ejército, así como a la explotación de las repúblicas más prósperas de Croacia y Eslovenia con el fin de proporcionar mayor bienestar a Serbia y las demás repúblicas, llevó a exigir una mayor autonomía por parte de Croacia y Eslovenia. En ese sentido, Dugard y Raic, “The role of recognition...”, pp. 123-124.

136 A este respecto, cabe citar a Marc Weller, quien advierte lo siguiente: "Si las discusiones dentro del orden constitucional no pueden producir resultados, o si a un lado le parece que ese orden está destinado a colocarlo en una posición de desigualdad y desventaja, no es sorprendente que la presión simplemente salga de ese marco a través de una declaración de la independencia. Croacia y Eslovenia adoptaron esa posición cuando las autoridades centrales de Belgrado no contemplaron un sistema federal más flexible para Yugoslavia. Belgrado había confiado en su dominio en las instituciones centrales yugoslavas, y en el hecho de que la independencia no parecía una alternativa posible. Al final, todo el Estado se disolvió como consecuencia [...] Por lo tanto, la lección del pasado puede ser que es bueno hablar". Weller, "Secession and Self-determination...". 
En el caso de Catalunya, aparentemente ésta no habría acreditado de manera suficiente y convincente ante la comunidad internacional el impedimento -u obstaculización- por parte del gobierno central español del ejercicio de su autonomía interna. Si bien, anteriormente podría haberse considerado la actitud del gobierno central como renuente a dialogar sobre el otorgamiento de un "pacto fiscal" o "concierto económico"137, por lo que de alguna manera podría haberse inferido la negativa o impedimento de ejercicio del aspecto económico (i.e., fiscal o presupuestario) de la autonomía interna del pueblo catalán ${ }^{138}$; tal posibilidad se desvanece ante la actual posición de apertura al diálogo respecto de un eventual "pacto fiscal" por parte del gobierno central español ${ }^{139}$.

Antes de concluir, es preciso reiterar los tres supuestos universalmente admitidos: (i) los pueblos colonizados; (ii) los pueblos ocupados; y, (iii) los pueblos sometidos a regímenes racistas. Como se explicó precedentemente, el pronunciamiento sobre la secesión de Quebec habría aportado otro supuesto teórico, cuya modalidad pacífica dependería fundamentalmente del respeto de ciertos parámetros propios de una democracia constitucional. Sin embargo, la modalidad unilateral se encontraría reconocida bajo el supuesto de la "secesión como remedio", cuya pretendida aplicación al caso kosovar aún es muy cuestionada. Asimismo, esta teoría podría haber desencadenado - probablemente sin pretenderlo- las secesiones de facto de Abjasia, Osetia del Sur y Crimea. Por tanto, lo más recomendable es ser prudentes respecto a la aplicabilidad o asimilación de la teoría de la "secesión como remedio" a la Opinión Consultiva sobre Kosovo.

Para concluir, cabe destacar que la vía idónea para ejercer el derecho a la libre determinación es la "secesión pactada" y pacífica (porque podría pactarse luego de un conflicto armado), aunque no sea muy frecuente en la práctica. Éste podría ser el caso de Escocia y Nueva Caledonia, y habría sido el de Quebec, de haberse acreditado el impedimento -u obstaculización- en el ejercicio de su autonomía interna. No obstante, sin duda alguna el Avis sobre la secesión de Quebec aportó principios y parámetros que permitirían tomar en cuenta las diferencias y así lograr una salida pacífica, los cuales deberían ser tomados en cuenta por toda -autodenominadademocracia constitucional.

137 Véase, la negativa del Tribunal Constitucional español a otorgar una mayor autonomía fiscal a Cataluña, TC de España, Sentencia 31/2010 de 28 de junio de 2010. Recurso de inconstitucionalidad 8045-2006, \ 118 y ss. Véase también, El País, "Rajoy rechaza el pacto fiscal por ser 'contrario a la Constitución", 20 de septiembre de 2012, disponible en: https://politica.elpais.com/politica/2012/09/20/actualidad/1348144748_908210.html.

138 Véase, por ejemplo, Costa, Josep, “¿Tiene Cataluña derecho de autodeterminación?”, Consejo de Diplomacia Pública de Cataluña, Catalonia Background Information [Serie E / 2017 / 2.1 / ES], 20 de abril de 2017, p. 2, disponible en: http://www.diplocat.cat/files/docs/170420-E02ES-CatalunaDerechoAutodeterminacion.pdf [Consultada 10 de agosto de 2018].

139 La V anguardia, "El Gobierno está dispuesto a negociar..."; The Guardian, "Spain 'ready to discuss'...”. 